\title{
MODEL KESESUAIAN LOKASI PENGEMBANGAN BUDIDAYA TAMBAK DI KAWASAN PESISIR KABUPATEN PONTIANAK, KALIMANTAN BARAT
}

\author{
Utojo, Akhmad Mustafa, dan Hasnawi \\ Balai Riset Perikanan Budidaya Air Payau \\ Jl. Makmur Dg. Sitakka No. 129, Maros, Sulawesi Selatan 90511 \\ E-mail: litkanta@indosat.net.id
}

(Naskah diterima: 15 Maret 2010; Disetujui publikasi: 12 Agustus 2010)

\begin{abstract}
ABSTRAK
Penelitian ini memanfaatkan teknologi Sistem Informasi Geografis (SIG) untuk menentukan lokasi yang sesuai bagi pengembangan budidaya tambak di Kabupaten Pontianak, Kalimantan Barat. Data sekunder yang diperoleh berupa data iklim, peta Rupabumi Indonesia kawasan Pontianak skala 1:50.000, citra digital ALOS AVNIR-2 dan peta batimetri skala 1:200.000. Data primer diperoleh dengan metode survai di lokasi penelitian yaitu kualitas air dan tanah serta pasang surut. Penentuan stasiun pengamatan dilakukan secara acak dan sistematik. Setiap lokasi pengambilan contoh ditentukan posisi koordinatnya dengan alat Global Positioning System (GPS). Data lapangan (fisika-kimia air dan tanah), data sekunder, dan data citra satelit digital, dianalisis secara spasial dengan metode PATTERN menggunakan SIG. Berdasarkan hasil survai dan evaluasi kesesuaian lokasi budidaya tambak di wilayah pesisir Kabupaten Pontianak seluas 497,077 ha. Pada umumnya yang tergolong sangat sesuai (1 14,986 ha), cukup sesuai (168,819 ha), tersebar di wilayah pesisir Kecamatan Sungai Pinyuh, Sungai Kunyit, Mempawah Hilir, dan Mempawah Timur, sedangkan yang kurang sesuai $(213,272 \mathrm{ha})$, terdapat di Kecamatan Segedong dan Siantan.
\end{abstract}

KATA KUNCl: kesesuaian lahan, tambak, Sistem Informasi Geografis, Pontianak

ABSTRACT: Site suitability modelling for brackhiswater pond development on shore area of Pontianak Regency, West Kalimantan. By: Utojo, Akhmad Mustafa, and Hasnawi

This research used GIS technique to find location suitable to develop sustainable brackhiswater pond in Pontianak Regency, West Kalimantan. Secondary data such as wheather data, Indonesia earth surface map of Pontianak area scale of 1:50,000, ALOS satellite imagery digital data, and navigation map scale 1:200,000 were collected and used. The primary data (water and soil quality) and tidal variation were determined during the field survey. Simple systematic random sampling was used to allocate sampling points. Digital Remote Sensing (ALOS) data, secondary data, and field data (water quality) were analyzed using PATTERN method and Geographical Information System (GIS). Thematic map of the area suitability as the main expected output of the study was created using spatial analysis and GIS as suggested by references. The potential areas suitable for brackhiswater pond development at Pontianak Regency were 497.077 ha, classified as brackhiswater pond with high suitability (114.986 ha) and moderate (168.819 ha), distributed in subdistrict shore area of Pinyuh River, Kunyit River, Mempawah Hilir, and Mempawah Timur, and the area classified as low suitability (213.272 ha) distributed in Segedong and Siantan Subdistricts. 


\section{KEYWORDS: land suitability, brackhiswater pond, Geographical Informa-} tion System, Pontianak

\section{PENDAHULUAN}

Kawasan pesisir yang memiliki topografi daratan landai, di mana pada saat pasang/ pasang tertinggi, air dapat menjangkau sampai ke daratan bagian dalam dan saat surut/surut terendah lahan tersebut kering kembali atau topografi daratan di atas ratarata pasang tertinggi, tanahnya bertekstur lempung liat berpasir atau lempung berpasir, sumber air laut dan sungainya relatif jernih merupakan kawasan yang potensial untuk budidaya tambak. Untuk mendapatkan kawasan tersebut, terlebih dahulu melakukan observasi lokasi budidaya tambak sesuai dengan komoditas yang dikelola dan teknologi yang diterapkan mulai dari pengelolaan secara tradisional sampai dengan intensif. Pada umumnya hasil penilaian kesesuaian lokasi pengembangan budidaya tambak sebagian besar hanya dapat diaplikasikan secara tradisional, tetapi yang potensial untuk budidaya tambak secara intensif relatif terbatas. Percepatan produksi budidaya tambak dapat terlaksana dengan baik, apabila didukung teknologi budidaya intensif secara berkelanjutan dengan memanfaatkan potensi hasil penilaian kesesuaian lokasi budidaya tambak yang ada.

Pada umumnya, suatu sumberdaya lahan pesisir peka terhadap perubahan lingkungan, apabila sumberdaya lahan tersebut dimanfaatkan dan dikelola dengan tujuan yang berbeda, akan menyebabkan terjadinya degradasi lingkungan, perubahan fungsi lahan, dan kerusakan ekosistem yang mengakibatkan berkurangnya sumberdaya perikanan.

Salah satu faktor untuk mencapai suatu keberhasilan usaha budidaya tambak, di samping biaya investasi, kualitas, dan karakter spesifik dari biota yang dibudidayakan, kedisiplinan operator, metode budidaya dengan teknologi yang diterapkan seperti desain, tata letak, dan konstruksi, serta tingkat produksi, juga harus mempertimbangkan karakteristik biofisik lokasi seperti biologi, hidrologi, meteorologi, kualitas tanah, dan air yang sesuai dengan daya dukung lingkungan wilayahnya (Radiarta et al., 2005).

Pemilihan lokasi budidaya tambak yang tepat merupakan tahap awal yang sangat penting untuk menentukan usaha budidaya secara berkelanjutan dan harus dilandasi dengan perencanaan yang tepat, menyeluruh, dan terpadu dengan rencana sektor lainnya, menjaga kelestarian sumberdaya dan lingkungan dengan mempertahankan karakteristik wilayah dan daya dukung lahan tetap stabil serta memperhatikan kepentingan sektor lain.

Untuk memudahkan dalam mendapatkan data dan informasi secara cepat dan akurat tentang kesesuaian lokasi pengembangan budidaya tambak yang disajikan dalam bentuk peta tematik dengan menggunakan teknologi informasi geografis (SIG) yang diintegrasikan dengan penginderaan jauh (inderaja). SIC memiliki kemampuan membuat model dalam rangka menyusun peta kesesuaian lahan yang disajikan secara cepat dan akurat untuk aktivitas yang berbeda, sedangkan inderaja memiliki kemampuan mengidentifikasi dan melakukan pemantauan terhadap perubahan sumberdaya alam dan lingkungan dalam periode tertentu secara cepat dan berkelanjutan serta data yang dihasilkan selalu yang terbaru (Hendiarti et al., 2006). Data inderaja yang diintegrasikan dengan SIG akan membentuk data base yang dapat menunjang kebutuhan pengelolaan wilayah pesisir dan lautan, khususnya untuk penyusunan tata ruang wilayah pesisir.

Tujuan penelitian ini untuk mendapatkan potensi dan kesesuaian lokasi pengembangan budidaya tambak dengan memanfaatkan teknologi SIG. Hasil dari penelitian ini diharapkan dapat menjadi masukan dan membantu dalam meningkatkan akurasi dan ketepatan rencana tata ruang wilayah yang telah disusun oleh pemerintah daerah dengan hasil survai mengenai lokasi dan luasannya untuk pengembangan budidaya tambak di wilayah tersebut.

\section{BAHAN DAN METODE}

Kegiatan riset pemetaan kesesuaian lokasi budidaya tambak dilaksanakan pada bulan Juli dan Agustus 2009 di wilayah pesisir Kabupaten Pontianak. Pemilihan lokasi survai masuk dalam perencanaan dan pengembangan tata ruang wilayah pesisir Pemerintah Daerah Provinsi Kalimantan Barat dan 
Kabupaten Pontianak yang menetapkan kawasan pesisir sebagai zonasi pengembangan perikanan budidaya tambak (Anonim, 2003a). Penyusunan tata ruang wilayah dilakukan dengan memperhatikan morfologi pantainya dan keragaman kawasan lokasi budidaya yang disurvai. Data dan informasi beberapa peubah kesesuaian lokasi tambak yang diperoleh dalam bentuk peta tematik, selanjutnya data tersebut oleh pengambil keputusan digunakan sebagai dasar untuk mengevaluasi tata ruang dan menetapkan sistem teknologi budidaya yang dapat dikembangkan.

Penelitian ini menggunakan metode survai yang dirancang berdasarkan Sistem Informasi Geografis (SIG). Pengamatan dan pengambilan sampel di lapangan berdasarkan metode transek dengan menentukan titik-titik pengamatan secara acak dan representatif serta jumlah titik pengamatannya ditentukan berdasarkan luas lokasi, kondisi lokasi, dan tingkat keseragaman lokasi (Duivenbooden, 1995). Posisi setiap pengamatan dan pengambilan sampel ditentukan koordinatnya dengan alat Global Positioning System (GPS). Contoh air dan tanah dianalisis di laboratorium. Metode pengambilan contoh air dan tanah serta metode analisisnya mengacu pada APHA (2005). Sebaran titik stasiun pengamatan di lokasi penelitian disajikan pada Gambar 1. Selain itu, juga dilakukan pengamatan mengenai vegetasi mangrove dan aspek penunjang lainnya.

Diagram alur analisis spasial pada pemetaan kesesuaian lokasi budidaya tambak dengan menggunakan teknologi SIG berdasarkan Utojo et al. (2009).

Data yang dikumpulkan dalam penelitian ini berupa data primer dan data sekunder. Data primer meliputi topografi pantai dan dasar perairan, jarak dari pantai, jarak dari sungai, tekstur tanah, $\mathrm{pH}$ yang diukur langsung di lapangan $\left(\mathrm{pH}_{\mathrm{F}}\right), \mathrm{pH}$ yang diukur setelah larutan dioksidasi dengan $\mathrm{H}_{2} \mathrm{O}_{2} 30 \%\left(\mathrm{pH}_{\mathrm{FOX}}\right)$, potensial redoks, $\mathrm{Fe}, \mathrm{Al}, \mathrm{SO}_{4}, \mathrm{PO}_{4}$, dan bahan organik total (Melville, 1993), pasang surut, sungai hidup/sumber air tawar. Kualitas air yang diamati meliputi salinitas, suhu, $\mathrm{pH}$, oksigen terlarut, $\mathrm{NO}_{2}, \mathrm{NH}_{4}, \mathrm{NO}_{3}, \mathrm{PO}_{4}, \mathrm{Fe}$, padatan tersuspensi total dan bahan organik total (APHA, 2005). Selain itu, juga diperlukan data dan informasi mengenai kemudahan mendapatkan air laut dan air tawar, frekuensi banjir, curah hujan, adanya jalur hijau, dan saluran irigasi. Faktor penunjang yang diamati meliputi ketersediaan jalan hingga lokasi, listrik, tenaga kerja, kemudahan memperoleh sarana produksi tambak, keamanan, dan pasar. Data sekunder berupa peta dasar dijital lokasi penelitian. Peta dasar ini bersumber dari hasil scan dan dijitasi peta rupabumi Indonesia skala 1:50.000, lembar 1316-24; 1316-31; 1316-33; dan 1316-52, tahun 2006 keluaran Badan Koordinasi Survei dan Pemetaan Nasional (Bakosurtanal) dan citra ALOS AVNIR-2, scene 10: ALAV2A155943590 dan ALAV2A15594 3600 tahun 2008, produksi Jepang.

Citra ALOS yang digunakan sudah terkoreksi geometrik, terkoreksi radiometrik, dan teregistrasi. Penajaman citra secara modifikasi kontras data citra dengan bantuan program "Er Mapper". Untuk mengurangi pengaruh cerah atau gelap dari titik citra di dalam citra, dilakukan pentapisan citra. Data citra ALOS memiliki 4 kanal dengan reduksi kanal menggunakan metode pemilihan kombinasi kanal spektral yang umum digunakan hanya 3 kanal yaitu kombinasi kanal 543 (Red Green Blue) dari sensor landsat ETM+. Hasil analisis menunjukkan bahwa kombinasi kanal 543 (Red Green Blue) dari sensor ALOS menampakkan secara jelas perbedaan spektral untuk setiap tutupan lahan pada wilayah daratan dan perairan, sehingga akan memudahkan pengklasifikasian secara tepat untuk lahan yang sesuai. Kemudian dilakukan klasifikasi yang nantinya dapat digunakan untuk membedakan penggunaan lahan secara tepat dan sesuai.

Informasi dari peta dasar meliputi morfologi dan garis pantai, sungai, garis batas wilayah, jalan, lumpur (sedimentasi), mangrove, penggunaan lahan, sebaran penduduk, letak dan nama lokasi, garis kontur atau ketinggian daratan dan kedalaman laut. Kriteria yang digunakan sebagai dasar skala penilaian dan bobot terhadap kesesuaian lokasi budidaya tambak mengacu pada persyaratan yang disarankan oleh Poernomo (1992) dan berdasarkan Utojo et al. (2009).

Evaluasi kesesuaian lokasi dilakukan dengan metode PATTERN (Planning Assisstance Through Technical Evaluation of Relevant Numbers) yang diterapkan untuk menghitung tingkat relatif dari kontribusi di setiap faktor lahan geografis sampai ke tujuan akhir. Faktor-faktor lahan geografis tersebut disajikan dalam bentuk peta-peta tematik, dan tujuan akhir adalah peta kesesuaian lokasi 


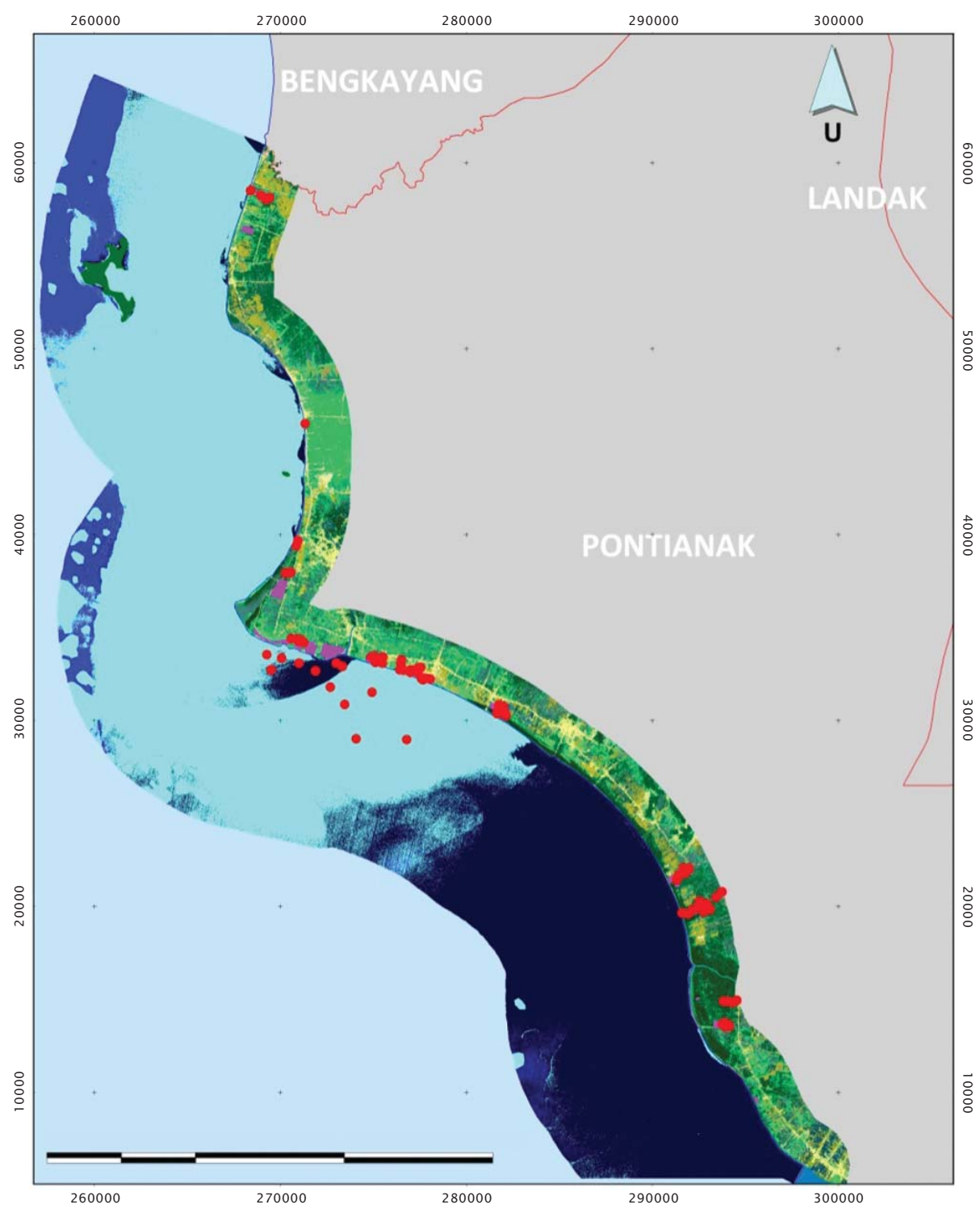

\begin{tabular}{|c|c|c|c|}
\hline \multicolumn{3}{|l|}{ Legenda/Legend: } & \multirow[t]{2}{*}{ Peta indeks: } \\
\hline Permukiman & Pulau & Batas administrasi & \\
\hline Vegetasi perdu & Laut dalam & & \\
\hline $\begin{array}{l}\text { Hutan } \\
\text { Lahan terbuka }\end{array}$ & Laut dangkal & Garis pantai & Lokasi \\
\hline $\begin{array}{l}\text { Lahan terbuka } \\
\text { Tegalan }\end{array}$ & $\begin{array}{l}\text { Laut keruh } \\
\text { Mangrove }\end{array}$ & Stasiun survey & \\
\hline Kebun & Vegetasi pantai & & \\
\hline Sawah & Rawa & & \\
\hline Tambak & Sungai & & \\
\hline
\end{tabular}

Gambar 1. Peta sebaran stasiun pengamatan kesesuaian lokasi budidaya tambak di Kabupaten Pontianak, Kalimantan Barat

Figure 1. Map of the research sampling station in Pontianak Regency, West Kalimantan 
budidaya tambak (Karthik et al., 2005). Pada metode ini setiap kategori di setiap faktor ditentukan dengan angka skor, dan total skor dihitung sebagai jumlah pembobotan dari setiap skor kategori. Bobot ditentukan melalui ketergantungan dari setiap faktor yang dikaitkan dengan tujuan (Treece, 2000). Penilaian terhadap tingkat kesesuaian lokasi budidaya tambak dilakukan secara kuantitatif melalui skoring dengan faktor pembobot berdasarkan Utojo et al. (2009).

Menurut Hidayat et al. (1995), skala penilaian pada kategori kesesuaian tinggi (S1), dalam tingkat pengelolaannya sangat didukung oleh peubah biofisik lokasi dan karakteristik lingkungannya serta produksinya tinggi. Kategori kesesuaian sedang (S2), dalam tingkat pengelolaannya mulai terjadi penurunan peubah biofisik lokasi, untuk meningkatkan produksi yang tinggi disarankan adanya input teknologi dan kategori kesesuaian rendah (S3), dalam tingkat pengelolaannya disertai dengan penurunan peubah biofisik lokasi yang berarti, produksinya rendah, untuk meningkatkan produksi mutlak harus ada input teknologi.

Data sekunder dan primer yang sudah dikumpulkan, selanjutnya diolah menggunakan analisis spasial dalam Sistem Informasi Geografis (SIG), bertujuan untuk menentukan kesesuaian lokasi budidaya tambak. Pada proses analisis peta tersebut dengan menggunakan perangkat lunak ArcView 3.3, data primer hasil survai pada setiap pengamatan dimasukkan dalam peta dasar digital dengan menginterpolasi pada setiap titik koordinat pengamatan menjadi area (polygon) menggunakan metode "Nearest Neighbour" (Morain, 1999). Dari hasil interpolasi setiap pengamatan, disusun dalam bentuk peta tematik dengan mempertimbangkan tingkat pembobotan dan skala penilaian serta melalui overlay (tumpang susun) untuk mendapatkan peta lokasi budidaya tambak dengan tingkat kesesuaian tinggi, sedang, dan rendah yang masing-masing disertai luasannya.

\section{HASIL DAN BAHASAN}

\section{Kondisi Umum Wilayah}

Kabupaten Pontianak memiliki 18 kecamatan dan 172 desa serta 7 kelurahan, luas wilayahnya $8262,10 \mathrm{~km}^{2}$ atau sekitar 5,63\% dari luas Provinsi Kalimantan Barat. Berdasarkan UURI No. 35 Tahun 2007, pada tanggal 17 Juli 2007 Kabupaten Kubu Raya diresmikan sebagai pemekaran wilayah dari Kabupaten Pontianak, masing-masing memiliki 9 kecamatan, walaupun dalam pelaksanaannya masih perlu pembenahan.

Sebagian besar wilayah Kabupaten Pontianak merupakan wilayah datar dengan kemiringan Iahan 0-2\%. Wilayah-wilayah dengan kemiringan lahan yang rendah ini menyebar dan memanjang dari utara ke selatan wilayah pesisir Kabupaten Pontianak pada ketinggian 0-25 m serta terbagi atas 9 kecamatan antara lain Kecamatan Sungai Pinyuh, Sungai Kunyit, Mempawah Hilir, Mempawah Timur, Segedong, Siantan, Anjongan, Toho, dan Kecamatan Sadaniang.

Kepadatan penduduk di Kabupaten Pontianak tahun 2007 sebanyak 218.949 jiwa dengan klasifikasi tertinggi pemukiman pantai antara lain di Kecamatan Mempawah Hilir, Sungai Pinyuh, dan Siantan. Terdapat cukup banyak pulau di wilayah Kabupaten Pontianak ini seperti Pulau Temajo di Kecamatan Sungai Kunyit, Pulau Damar dan Setinjam di Kecamatan Mempawah Hilir, Pulau Datuk di Kecamatan Sungai Pinyuh, Pulau Panjang, Babi, Bumin, dan Pulau Baru di Kecamatan Siantan. Secara geografis Kabupaten Pontianak terletak pada posisi antara $108^{\circ} 35^{\prime}-109^{\circ} 58^{\prime}$ Bujur Timur dan $0^{\circ} 44^{\prime}-1^{\circ} 01^{\prime}$ Lintang Selatan dengan batas wilayah sebelah utara berbatasan dengan Kabupaten Bengkayang, sebelah selatan dengan Kabupaten Ketapang, sebelah timur dengan Kabupaten Landak, dan sebelah barat dengan Laut Natuna (Anonim, 2003b; 2007).

Morfologi pantai di Kabupaten Pontianak umumnya bertopografi landai, terbentang mulai dari sebelah utara hingga selatan, letaknya memanjang dan sempit dengan batas terjauh dari pantai sekitar $97 \mathrm{~km}$ yaitu batas sebelah timur Kecamatan Ambawang. Wilayah yang memiliki kemiringan lebih dari $2 \%$ banyak dijumpai di bagian perbatasan timur laut kabupaten yang merupakan kawasan perbukitan. Tipe garis pantainya berkelokkelok, berhadapan dengan Laut Natuna, sebagian besar jenis tanahnya alluvial dan organosol terdapat di semua kecamatan, kecuali yang bergambut dengan ketinggian 10-20 cm terdapat di Kecamatan Segedong.

Daerah vegetasi mangrove merupakan daerah penyedia sumberdaya perikanan pesisir dan pelindung pantai dari gelombang besar serta angin kencang, yang dalam 
pemanfaatan secara terkendali dapat pulih kembali. Untuk itu, harus dilakukan dengan tepat agar tidak melebihi kemampuannya untuk memulihkan diri pada periode tertentu sehingga efeknya tidak merusak lingkungan sekitarnya. Terjadinya kerusakan ekosistem mangrove di setiap kabupaten, terutama diakibatkan belum adanya kejelasan tentang tata ruang dan rencana pengembangan wilayah pesisir sehingga banyak terjadi tumpang tindih pemanfaatan kawasan hutan mangrove untuk berbagai kegiatan pembangunan seperti pemukiman, pertambakan, dan kawasan industri secara tidak terkendali (Wirasantosa, 2004).

Vegetasi mangove di sepanjang kawasan pesisir Kabupaten Pontianak bervariasi dan hidupnya tersebar di beberapa kecamatan seperti di Kecamatan Mempawah Hilir didominasi oleh Avicenia; Kecamatan Mempawah Timur didominasi oleh Avicenia, nipah, dan paku-pakuan; Kecamatan Segedong didominasi oleh kelapa, alang-alang, dan semak belukar; Kecamatan Sungai Pinyuh, Sungai Kunyit; dan Siantan didominasi oleh kelapa, Avicenia, dan paku-pakuan. Wilayah pesisir di Kecamatan Mempawah Hilir dan Sungai Kunyit memiliki proses abrasi pantai sangat kuat disebabkan adanya arus yang kuat dan tipisnya jalur hijau di sepanjang pantai. Variasi jenis vegetasi yang tumbuh di kawasan pesisir pada beberapa kecamatan diduga banyak dipengaruhi oleh karakteristik tanah dan pengaruh salinitas serta perbedaan pasang surut. Menurut Bengen (2004), karakteristik habitat hutan mangrove umumnya tumbuh pada daerah intertidal yang jenis tanahnya berlumpur, berlempung atau berpasir, menerima pasokan air tawar yang cukup atau mendapatkan air bersalinitas payau (2-22 ppt) hingga asin (mencapai 38 ppt), dan terlindung dari gelombang besar dan arus pasang surut yang kuat.

Untuk mengatasi abrasi pantai yang kuat, politeknik perikanan Kabupaten Pontianak telah menanam pohon Avicenia di sepanjang pantai wilayah pesisir Kecamatan Mempawah Hilir. Lebar jalur hijau di sepanjang pantai berkisar 50-150 m, memiliki elevasi pantai 0-5 m dengan kemiringan pantai 0\%-2\%. Pada wilayah pantai ini, banyak terdapat areal dataran yang relatif rendah dari permukaan pasang air laut tertinggi sehingga sangat rawan mengalami banjir seperti yang terjadi di Kecamatan Mempawah Hilir, Segedong, dan
Siantan. Keadaan banjir ini terjadi pada saat air dalam keadaan pasang terutama pada bulan-bulan yang memiliki curah hujan tinggi yaitu sekitar bulan Desember dan Januari. Untuk mengatasi permasalahan tersebut, pemerintah daerah Pontianak telah melakukan pembuatan tanggul di sepanjang pantai pada wilayah yang terkena banjir.

Di Kabupaten Pontianak terdapat 2 musim yaitu musim kemarau dan penghujan. Musim kemarau terjadi pada bulan Maret hingga Juli dan musim penghujan terjadi pada bulan Agustus hingga Februari. Secara umum ratarata curah hujan di Kabupaten Pontianak berkisar $755 \mathrm{~mm} /$ tahun atau rata-rata 62 $\mathrm{mm} /$ bulan. Rata-rata curah hujan tertinggi terjadi pada bulan Desember sebesar $129 \mathrm{~mm}$, sedangkan rata-rata curah hujan terendah terjadi pada bulan Juli sebesar $1 \mathrm{~mm}$. Wilayah daratannya terdapat banyak sungai yang mengalir ke laut dengan kerapatan relatif tinggi. Sungai Mempawah di Kecamatan Mempawah Hilir merupakan sungai induk yang berguna untuk mengairi kawasan pertambakan sekitarnya, pada saat musim penghujan kondisi sungainya keruh yang disebabkan oleh erosi lahan bagian atas. Kedalaman muara sungainya sekitar 1,9 m dengan substrat dasar lempung berpasir yang selanjutnya sedimen tersebut tersebar ke perairan laut. Kawasan pertambakan di Kecamatan Mempawah Hilir umumnya menggunakan sumber air dari sungai, sehingga perlu dipertimbangkan dan diupayakan remediasinya baik untuk intensifikasi maupun ekstensifikasi budidaya tambak. Kekeruhan pada sungai tersebut juga disebabkan oleh bahan-bahan tersuspensi hasil dari erosi lapisan permukaan tanah yang terbawa oleh aliran air pada saat hujan. Kekeruhan yang tinggi dapat mengakibatkan terganggunya sistem osmoregulasi, pernafasan dan daya lihat organisme akuatik serta dapat menghambat penetrasi cahaya ke dalam air. Tingginya nilai kekeruhan juga dapat mempersulit usaha penyaringan dan mengurangi efektivitas desinfeksi pada proses penjernihan air (Effendi, 2003).

Pada umumnya perairan pantai di Kabupaten Pontianak termasuk perairan laut dangkal, dengan jarak sekitar $5 \mathrm{~km}$ dari garis pantai memiliki kedalaman berkisar 1,9-6 m, pada saat musim kemarau, kondisi airnya relatif jernih dan saat musim penghujan, kondisi airnya keruh berwarna coklat yang disebabkan 
sedimentasi dari daratan, bentuk dasar lautnya bergelombang dengan substrat dasar lempung berpasir dan salinitasnya berkisar 24,68-29,06 ppt. Kawasan pertambakan di kecamatan lain yang menggunakan sumber air laut, juga perlu dipertimbangkan dan diupayakan remediasinya baik untuk intensifikasi maupun ekstensifikasi tambak. Untuk mengatasi perbaikan kualitas air budidaya tambak intensif dengan menggunakan tandon berlapis, di mana tandon air pertama, hasil filterisasi secara fisik dengan kedalaman $4 \mathrm{~m}$ dan tandon air kedua, hasil biofilterisasi atau bioremediasi (rumput laut, bandeng, dan kekerangan) dengan kedalaman $2 \mathrm{~m}$. Air dari tandon pertama dialirkan ke tandon kedua dan selanjutnya dialirkan ke petak-petak tambak. Untuk budidaya tambak ekstensif hanya menggunakan tandon air hasil filterisasi secara fisik.

Keseragaman kondisi lahan tambak dan jenis tanahnya alluvial dan organosol serta tekstur tanahnya lempung liat berpasir pada kedalaman 0-0,5 m, kemungkinan disebabkan adanya akumulasi sedimen secara kontinu dalam kurun waktu yang lama. Bahan induk sedimen berasal dari erosi lahan di bagian hulu, yang terbawa aliran sungai dan tersebar di sepanjang pantai.

Pemerintah daerah Kabupaten Pontianak telah membuat dan menyusun rencana tata ruang wilayah yang ditetapkan berdasarkan Keppres Nomor 32 Tahun 1990. Rencana tata ruang kawasan budidaya perikanan laut dan perikanan payau (tambak) akan dikembangkan di semua kecamatan yang berbatasan dengan Laut Natuna dengan kawasan pengembangan utama di Kecamatan Mempawah Hilir dan Sungai Kunyit. Pengembangan kawasan budidaya perikanan darat diprioritaskan di 2 kecamatan yaitu Kecamatan Anjongan dan Mempawah Hilir (Anonim, 2007).

\section{Kualitas Tanah}

Penentuan kesesuaian lokasi budidaya tambak, kualitas tanah juga memegang peranan penting dan banyaknya sampel tanah yang didapatkan di lokasi survai, tergantung dari luas wilayah dan heterogenitas vegetasi di sekitar tambak dengan memiliki koordinat 01 '48"-0³6'0" Lintang Utara dan 10847'60"$109^{\circ} 15^{\prime} 0$ " Bujur Timur (Tabel 1). Hasil analisis tekstur tanah pada kedalaman 0-0,5 m cukup bervariasi mulai dari lempung berdebu, lempung berpasir, pasir berlempung, sampai dengan lempung liat berpasir, sedangkan fraksi liat hanya didapatkan pada permukaan tanah. Tekstur tanah tersebut didominasi oleh fraksi lempung dan debu yang berasal dari hulu daerah aliran sungai, sedangkan fraksi pasir berasal dari laut akibat adanya arus susur pantai dan sebagian besar didapatkan di lokasi tambak yang relatif sedikit mangrovenya. Menurut Poernomo (1992), tekstur tanah tambak yang baik untuk budidaya udang tradisional dan semi-intensif yaitu lempung liat berpasir, sedangkan tekstur tanah tambak udang intensif yaitu lempung liat berpasir hingga lempung berpasir. Pada tambak udang intensif diperlukan dasar tambak yang kompak dan keras agar dapat menyimpan air saat pelaksanaan budidaya sampai dengan panen.

Nilai $\mathrm{pH}$ tanah tambak di bagian atas 5,467,30 dan kedalaman 0,5 m yaitu 5,68-7,02 relatif sama. Kondisi pH tanah tersebut didapatkan pada tambak lama, hasil akumulasi bahan organik dari sisa-sisa vegetasi dan potensi kemasamannya rendah. Rendahnya $\mathrm{pH}_{\mathrm{FOX}}$ tanah tambak di bagian atas 1,82-5,30 dan kedalaman $0,5 \mathrm{~m}$ yaitu 1,22-4,73 didapatkan di lokasi tambak yang telah diremediasi, saat teroksidasi, tingkat kemasaman tanah agak tinggi. Nilai $\mathrm{pH}$ tanah tambak secara umum baik dan mendukung kegiatan budidaya tambak.

Secara alami, hasil proses dekomposisi bahan organik dan kandungan pirit yang berlebihan di dalam tanah dasar tambak dalam kondisi anaerob sebagai sumber senyawa besi yang sukar larut. Pada pH sekitar 7 dengan oksigen terlarut yang cukup, ion ferro $\left(\mathrm{Fe}^{2+}\right)$ yang mudah larut dioksidasi menjadi ion ferri $\left(\mathrm{Fe}^{3+}\right)$ dan terjadi pelepasan elektron, sebaliknya pada proses reduksi, ion ferri menjadi ion ferro dan terjadi penangkapan elektron serta melibatkan bakteri sebagai mediator.

Nilai potensial reduksi dan oksidasi tanah dasar tambak di bagian atas dan kedalaman $0,5 \mathrm{~m}$ berkisar (-217)-(+1 14) $\mathrm{mV}$ dan (-282)$(+160) \mathrm{mV}$. Kisaran nilai tersebut masih dalam kategori baik untuk kegiatan budidaya tambak terutama dalam pertukaran ion dan peran bakteri sebagai mediator. Umumnya reaksi kimiawi yang terjadi pada perairan dalam kondisi aerob memiliki nilai potensial redoks $>200 \mathrm{mV}$, sedangkan reaksi kimiawi dalam kondisi anaerob memiliki nilai potensial redoks $<50 \mathrm{mV}$ (Tebbut, 1992). Pada lumpur dasar perairan yang memiliki kondisi anaerob, nilai potensial redoks dapat mencapai $-0,1$ Volt (Boyd, 1988). Kondisi tanah di dasar tambak 
Tabel 1. Kisaran nilai peubah tekstur dan kualitas tanah di lokasi tambak Kabupaten Pontianak, Kalimantan Barat

Table 1. Value range of soil quality parameters at brackishwater pond location of Pontianak Regency, West Kalimantan

\begin{tabular}{|c|c|c|c|}
\hline $\begin{array}{l}\text { Peubah kualitas tanah } \\
\text { Soil quality parameters }\end{array}$ & $\begin{array}{l}\text { Kedalaman } \\
\text { Depth (m) }\end{array}$ & $\begin{array}{l}\text { Kisaran nilai } \\
\text { Value range }\end{array}$ & $\begin{array}{l}\text { Nilai ideal } \\
\text { Ideal value }\end{array}$ \\
\hline $\begin{array}{l}\text { Tekstur (Texture ): } \\
\text { - Pasir (Sand ) (\%) } \\
\text { - Liat (Clay ) (\%) } \\
\text { - Debu (Silt ) (\%) }\end{array}$ & $\begin{array}{c}0 \\
44-74 \\
2-32 \\
12-52\end{array}$ & $\begin{array}{c}\text { Lempung berdebu, pasir } \\
\text { berlempung, lempung berpasir, } \\
\text { dan lempung liat berpasir (Silty } \\
\text { clay, clay sand, sandy clay, and } \\
\text { sandy claley clay ) }\end{array}$ & $\begin{array}{l}\text { Lempung liat berpasir (Sandy claley } \\
\text { clay ): tambak tradisional - semi- } \\
\text { intensif (traditional - intensive } \\
\text { pond ) }\end{array}$ \\
\hline $\begin{array}{l}\text { Tekstur (Texture ): } \\
\text { - Pasir (Sand ) (\%) } \\
\text { - Liat (Clay ) (\%) } \\
\text { - Debu (Silt ) (\%) }\end{array}$ & $\begin{array}{c}0,5 \\
44-76 \\
2-20 \\
10-54\end{array}$ & $\begin{array}{l}\text { Lempung berpasir, lempung } \\
\text { berdebu, dan pasir berlempung } \\
\text { (Sandyclay, siltyclay, and clay } \\
\text { sand ) }\end{array}$ & $\begin{array}{l}\text { Lempung berpasir (Sandyclay ): } \\
\text { tambak intensif (intensive pond ) }\end{array}$ \\
\hline $\mathrm{pH}_{\mathrm{F}}$ & $\begin{array}{c}0 \\
0.5\end{array}$ & $\begin{array}{l}5.46-7.30 \\
5.68-7.02\end{array}$ & $\left.6.5-7.0^{*}\right)$ \\
\hline $\mathrm{pH}_{\text {FOx }}$ & $\begin{array}{c}0 \\
0.5\end{array}$ & $\begin{array}{l}182-5.30 \\
122-4.73\end{array}$ & \\
\hline $\begin{array}{l}\text { Potensial redoks } \\
\text { Redoxpotential }\end{array}$ & $\begin{array}{c}0 \\
0.5\end{array}$ & $\begin{array}{l}(-217)-(+114) \\
(-282)-(+160)\end{array}$ & Minimal (Minimum $)+50 \mathrm{mV}^{*}$ ) \\
\hline $\mathrm{SO}_{4}(\mathrm{mg} / \mathrm{L})$ & $\begin{array}{c}0 \\
0.5\end{array}$ & $\begin{array}{l}1,030-88,680 \\
1,402-94,100\end{array}$ & $\begin{array}{l}\text { Tergantung kandungan pirit yang } \\
\text { teroksidasi saat kering (Depend } \\
\text { on pyrite content that oxydated } \\
\left.\text { when dry })^{*}\right)\end{array}$ \\
\hline $\mathrm{PO}_{4}(\mathrm{mg} / \mathrm{L})$ & $\begin{array}{c}0 \\
0.5\end{array}$ & $\begin{array}{r}0.00-65.69 \\
0.00-100.21\end{array}$ & $\begin{array}{l}>60 \mathrm{mg} / \mathrm{L} \text { : tambak tradisional (for } \\
\text { tradisional pond ), tambak intensif } \\
\quad \text { kurang diperlukan (not } \\
\text { necessaried for intensive pond })^{\star \star \star} \text { ) }\end{array}$ \\
\hline $\begin{array}{l}\text { Bahan Organik Total } \\
\text { Total organic matter (\%) }\end{array}$ & $\begin{array}{c}0 \\
0.5\end{array}$ & $\begin{array}{r}0.14-9.69 \\
0.55-15.55\end{array}$ & $\begin{array}{l}137.50 \mathrm{mg} / \mathrm{L}: \text { tambak intensif s/d } \\
\text { minggu ke-14 (Resulted from } \\
\text { intensive pond to weeks of the } \\
\left.\text { fourteen })^{\star}\right)\end{array}$ \\
\hline $\mathrm{Fe}(\mathrm{mg} / \mathrm{L})$ & $\begin{array}{c}0 \\
0.5\end{array}$ & $\begin{array}{c}9.75-626.75 \\
2125-4,713.00\end{array}$ & $\begin{array}{l}\text { Tergantung kandungan pirit yang } \\
\text { teroksidasi saat kering (Depend } \\
\text { on pyrite content that oxydated } \\
\left.\text { when dry })^{*}\right)\end{array}$ \\
\hline $\mathrm{Al}(\mathrm{mg} / \mathrm{L})$ & $\begin{array}{c}0 \\
0.5\end{array}$ & $\begin{array}{l}25.25-93.00 \\
7.25-18100\end{array}$ & Sama dengan di atas (Same up ) \\
\hline
\end{tabular}

Sumber (Source): ") Poernomo (1992); "*) Boyd dalam Widigdo (2003); ***) Karthik et al. (2005)

yang tergenang (anaerob), laju oksidasi dan proses perombakan bahan organik lebih lambat, tetapi memiliki laju pereduksi sulfur dan besi lebih cepat daripada di dasar tambak yang kering (aerob). Variasi nilai potensial redoks tergantung dari perbedaan tekstur dan banyaknya kandungan bahan organik dalam tanah. Tanah dasar tambak yang bertekstur dominan pasir dalam kondisi aerob laju oksidasi lebih cepat daripada yang memiliki banyak kandungan bahan organik (Noor, 2004). Untuk mengembalikan kondisi dasar tambak yang baik diperlukan nilai potensial redoks minimal + $50 \mathrm{mV}$ dengan nilai pH 6,5-8,5 (Boyd dalam Widigdo, 2003).

Konsentrasi $\mathrm{SO}_{4}$ dan $\mathrm{Fe}$ tanah di bagian atas tambak 1.030-88.680 mg/L dan 9,75$626,75 \mathrm{mg} / \mathrm{L}$, sedangkan di kedalaman $0,5 \mathrm{~m}$ yaitu 1.402-94.100 mg/L dan 21,25-4.713,00 
mg/L. Kisaran nilai $\mathrm{SO}_{4}$ dan $\mathrm{Fe}$ tanah tersebut masih baik untuk kegiatan budidaya tambak, walaupun perlu proses remediasi. Tingginya nilai $\mathrm{SO}_{4}$ dan Fe di kedalaman $0,5 \mathrm{~m}$, didapatkan di lokasi tambak bekas mangrove dan tanaman rawa pantai yang di dalamnya terdapat konsentrasi pirit 0,57\%-1,15\% dan tergolong dalam tanah sulfat masam.

Tanah sulfat masam adalah tanah atau sedimen yang mengandung pirit $\left(\mathrm{FeS}_{2}\right)$, pada kondisi kering dapat teroksidasi akan melarutkan $\mathrm{SO}_{4}$ dan Fe serta menghasilkan kondisi kemasaman yang tinggi atau terjadi penurunan $\mathrm{pH}$ tanah. Penurunan $\mathrm{pH}$ tanah berdampak pula pada peningkatan kelarutan Al seperti terlihat pada Tabel 1, di mana konsentrasi Al yang tinggi umumnya didapatkan di tanah tambak bagian atas yaitu 25,25-93,00 mg/L, dan tingginya konsentrasi Al di kedalaman 0,5 m mencapai 181,00 mg/L karena pada lapisan tanah sampai kedalaman tersebut masih terdapat pirit dengan konsentrasi 1,15\%. Menurut Poernomo (1992), pengembangan rawa pantai di kawasan intertidal yang tertutup vegetasi mangrove menjadi pertambakan, tanahnya mengandung pirit. Setelah selesai konstruksi dan pengeringan, tanah dasar tambak memiliki tingkat kemasaman tinggi $(\mathrm{pH}$ 2,5-5,0) dan kemasaman akan meningkat setelah pirit teroksidasi.

Konsentrasi fosfat tanah tambak yang didapatkan di bagian atas 0,00-65,69 mg/L dan di kedalaman $0,5 \mathrm{~m}$ yaitu $0,00-100,21 \mathrm{mg} / \mathrm{L}$, tergolong rendah hingga tinggi. Di tambak, fosfat merupakan bentuk fosfor anorganik, larut dalam air, sebagai unsur esensial yang langsung dapat dimanfaatkan dan menjadi faktor pembatas bagi tanaman dan alga akuatik serta sangat mempengaruhi terhadap tingkat produktivitas primer, yang selanjutnya dapat meningkatkan produksi ikan herbivor di tambak (Effendi, 2003). Ketersediaan fosfat $>60 \mathrm{mg} / \mathrm{L}$ dalam tanah tambak, tergolong baik untuk peningkatan kesuburan perairan tambak (Karthik et al., 2005). Tanah tambak yang memiliki konsentrasi fosfat tinggi $(65,69$ $100,21 \mathrm{mg} / \mathrm{L}$ ), baik untuk kegiatan budidaya tambak tradisional dan rumput laut. Tanah tambak yang miskin unsur fosfat $(0,00 \mathrm{mg} / \mathrm{L})$, baik untuk kegiatan budidaya tambak intensif yang lebih mengutamakan pakan buatan sebagai pakan utama udang.

Konsentrasi bahan organik total tanah tambak di bagian atas 0,14\%-9,69\% dan di kedalaman $0,5 \mathrm{~m}$ yaitu $0,55 \%-15,55 \%$, tergolong rendah dan baik untuk kegiatan budidaya tambak intensif.

\section{Kualitas Air}

Pada umumnya perairan pantai di Kabupaten Pontianak yang disurvai rata-rata memiliki sumber air yang cukup menunjang untuk kegiatan budidaya tambak karena lokasinya berdekatan dengan laut, sungaisungainya cukup lebar, dan terdapat saluran pemasukan utama yang dapat menjangkau semua unit pertambakan sehingga tambaknya terjangkau pasang surut air laut. Perairan lautnya terbuka dan dangkal dengan jarak 5 $\mathrm{km}$ dari garis pantai ke arah laut memiliki kedalaman 1,9-6 m. Saat ini perairan laut tersebut sebagai sumber pemasok utama unit pertambakan di wilayah pesisir, pada saat musim kemarau kondisi perairannya relatif jernih dan saat musim penghujan perairannya keruh berwarna coklat yang disebabkan sedimentasi dari daratan bagian hulu, topografi dasar lautnya bergelombang dengan substrat dasar pasir dominan lumpur dengan salinitas berkisar 24,68-29,06 ppt (Tabel 2).

Hasil pengukuran dan analisis kualitas air di perairan laut Kabupaten Pontianak dan muara sungai di beberapa kecamatan, umumnya masih baik untuk pengembangan wilayah budidaya tambak secara intensifikasi (udang) dan ekstensifikasi (udang, rumput laut, dan bandeng). Kondisi perairan di muara Sungai dan Sungai Purun, Kecamatan Segedong, memiliki nilai padatan tersuspensi total cukup tinggi, masing-masing 372 dan 560 $\mathrm{mg} / \mathrm{L}$ terutama kandungan lumpur halus yang disebabkan erosi tanah di bagian hulu sungai. Berdasarkan Alabaster \& Lioyd (1982) dalam Effendi (2003), nilai padatan tersuspensi $<25$ $\mathrm{mg} / \mathrm{L}$, baik untuk budidaya perikanan; 25-80 $\mathrm{mg} / \mathrm{L}$, sedikit berpengaruh untuk budidaya perikanan; 81-400 mg/L, kurang baik untuk budidaya perikanan dan $>400 \mathrm{mg} / \mathrm{L}$, tidak baik untuk budidaya perikanan. Kawasan pertambakan di semua kecamatan yang dekat laut, di sekitar Muara Sungai Purun, Kecamatan Segedong dan Muara Sungai Mempawah, Kecamatan Mempawah Hilir dengan menggunakan sumber air dari laut dan sungai, yang airnya keruh saat musim penghujan, perlu dipertimbangkan dan diupayakan remediasinya baik untuk intensifikasi maupun ekstensifikasi budidaya tambak. 
Hasil pengukuran langsung dan analisis pasang surut di Muara Sungai Mempawah, Kecamatan Mempawah Hilir, didapatkan perbedaan pasang surut yang cukup besar yaitu 160 dan $305 \mathrm{~cm}$ dengan tunggang pasang $145 \mathrm{~cm}$. Kondisi pasang surut tersebut cukup berpengaruh terhadap kuantitas dan kualitas air sebagai media budidaya tambak. Laju kecepatan aliran air selama pasang tinggi untuk mengairi tambak di Kabupaten Pontianak dipengaruhi oleh frekuensi amplitudo pasang, kontur tanah, dan elevasi. Pada umumnya wilayah yang dekat pantai memiliki elevasi 1-1,5 m yang posisinya lebih rendah dari rataan pasang tertinggi yaitu $305 \mathrm{~cm}$ dan lebih tinggi dari rataan surut terendah yaitu $160 \mathrm{~cm}$, posisi lokasi tambak tersebut secara gravitasi cukup baik yaitu dapat dikeringkan saat konstruksi unit tambak, persiapan tambak dan panen serta dapat mengganti air dengan mudah saat pelaksanaan tambak. Menurut Poernomo (1992), pelaksanaan budidaya ekstensif dan semi-intensif di kawasan intertidal dengan pergantian air secara gravitasi saat pasang dan lokasi dengan elevasi sedang serta dapat dikeringkan saat surut terendah merupakan lokasi yang ideal untuk pembangunan unit tambak.

Nilai suhu $29,31^{\circ} \mathrm{C}-31,57^{\circ} \mathrm{C}$, didapatkan di lokasi di tambak udang vaname intensif yang sedang aktif dengan kedalaman 0,5-1,2 $\mathrm{m}$ dan nilai suhu $32,41^{\circ} \mathrm{C}-37,79^{\circ} \mathrm{C}$, di lokasi tambak tradisional. Tingginya nilai suhu tersebut didapatkan di pertambakan tradisional, dinilai masih baik untuk kegiatan budidaya tambak. Menurut Poernomo (1992), suhu optimum budidaya tambak udang $29^{\circ} \mathrm{C}-31^{\circ} \mathrm{C}$, kecepatan dan besarnya konsumsi oksigen meningkat seiring dengan meningkatnya suhu serta udang tumbuh pesat pada suhu $30^{\circ} \mathrm{C}-31^{\circ} \mathrm{C}$. Nilai pH yang didapatkan di lokasi survai 6,94-8,78. Kisaran nilai pH tambak tersebut umumnya netral hingga alkalis dan masih dalam batas yang layak sebagai media budidaya tambak udang. Pada tambak yang sudah lama beroperasi umumnya $\mathrm{pH}$ air alkalis 7,5-8,5, sedangkan tambak baru di kawasan mangrove dan belum diremediasi, $\mathrm{pH}$ air sangat rendah yaitu di bawah 5 . Pengaruh langsung $\mathrm{pH}$ rendah yaitu udang menjadi keropos dan selalu lembek, pH tinggi dapat meningkatkan konsentrasi ammonia yang selanjutnya dapat mengakibatkan kematian udang. Nilai pH optimum sebagai media budidaya tambak udang 8,0-8,5 dan nilai $\mathrm{pH}$ yang diperbolehkan sebagai baku mutu air laut untuk biota laut 7-8,5 (Poernomo, 1988; 1992; KLH, 2004).

Nilai konsentrasi oksigen terlarut di lokasi survei 2,58-8,39 mg/L. Kisaran nilai konsentrasi oksigen terlarut tersebut masih baik untuk kegiatan budidaya tambak. Nilai konsentrasi oksigen terlarut 2,58-6,80 mg/L, didapatkan di pertambakan bandeng tradisional, banyak klekap dan lumut, sehingga oksigen terlarut sangat berfluktuatif pada pagi, siang, sore, dan malam hari. Menurut Effendi (2003), konsentrasi oksigen terlarut di perairan alami biasanya kurang dari $10 \mathrm{mg} / \mathrm{L}$ dan berfluktuasi secara harian dan musiman, tergantung pada pencampuran dan pergerakan massa air, aktivitas fotosintesis, respirasi, dan limbah yang masuk ke badan air. Nilai konsentrasi oksigen terlarut 6,63-8,39 mg/L, didapatkan di pertambakan udang vaname intensif yang dilengkapi dengan kincir air sehingga dapat menstabilkan konsentrasi oksigen terlarut dalam tambak. Perairan yang diperuntukkan bagi budidaya perikanan sebaiknya memiliki konsentrasi oksigen terlarut tidak kurang dari $5 \mathrm{mg} / \mathrm{L}$. Konsentrasi oksigen terlarut yang kurang dari $2 \mathrm{mg} / \mathrm{L}$ dapat mengakibatkan kematian ikan. Udang dapat hidup dan tumbuh dengan baik di tambak, jika konsentrasi oksigen terlarut 4-7 mg/L. Konsentrasi oksigen terlarut terlalu rendah atau tinggi menyebabkan laju pertumbuhan udang lambat (Poernomo, 1988).

Nilai konsentrasi amonia $\left(\mathrm{NH}_{3}\right)$ di lokasi survai $0,0095-0,2652 \mathrm{mg} / \mathrm{L}$, masih baik sebagai media budidaya tambak. Nilai konsentrasi amonia optimum tambak udang $0,25 \mathrm{mg} / \mathrm{L}$ (Poernomo, 1992; KLH, 2004). Tingginya konsentrasi amonia $(0,2652 \mathrm{mg} / \mathrm{L})$ didapatkan di pertambakan bandeng tradisional, banyak klekap yang mati dan serasah, ditandai dengan konsentrasi amonia yang terakumulasi di dasar perairan tambak. Menurut Effendi (2003), amonia jarang didapatkan di perairan yang cukup pasokan oksigen dan konsentrasi amonia yang tinggi terdapat di dasar perairan tanpa oksigen. Amonia bebas $\left(\mathrm{NH}_{3}\right)$ tidak dapat terionisasi dan bersifat toksik terhadap organisme akuatik, sedangkan amonium $\left(\mathrm{NH}_{4}^{+}\right)$ dapat terionisasi dan tidak bersifat toksik terhadap organisme akuatik. Konsentrasi amonia di perairan alami biasanya kurang dari $0,1 \mathrm{mg} / \mathrm{L}$. Toksisitas amonia terhadap organisme akuatik akan meningkat jika terjadi penurunan konsentrasi oksigen terlarut, 
Tabel 2. Kisaran nilai peubah kualitas air di tambak Kabupaten Pontianak, Kalimantan Barat

Table 2. Value range of water quality parameters in the brackishwater pond of Pontianak Regency, West Kalimantan

\begin{tabular}{|c|c|c|c|}
\hline $\begin{array}{c}\text { Peubah kualitas air } \\
\text { Water quality parameters }\end{array}$ & $\begin{array}{l}\text { Satuan } \\
\text { Unit }\end{array}$ & $\begin{array}{l}\text { Kisaran nilai } \\
\text { Value range }\end{array}$ & $\begin{array}{l}\text { Nilai ideal } \\
\text { Ideal value }\end{array}$ \\
\hline \multicolumn{4}{|l|}{ Salinitas (Salinity): } \\
\hline - Laut (Sea) & ppt & $24.68-29.06$ & $30-35^{*}$ \\
\hline - Muara sungai (Estuarine) & ppt & $25.04-26.06$ & $25-30$ \\
\hline - Sungai (River) & ppt & $16.50-25.36$ & $10-25^{*}$ \\
\hline - Saluran (Canal) & ppt & $12.65-34.68$ & $10-25^{*}$ \\
\hline - Tandon (Reservoar) & ppt & $14.10-26.57$ & $10-25^{*}$ \\
\hline - Tambak (Brackishwater pond) & $\mathrm{ppt}$ & $9.46-31.08$ & $15-25^{*}$ \\
\hline Suhu (Temperature) & ${ }^{\circ} \mathrm{C}$ & $29.31-32.41$ & $29-31 *$ \\
\hline $\mathrm{pH}$ & & $6.94-8.78$ & $7.0-8.5^{* \prime \prime}$ \\
\hline Tunggang pasang surut (Tidal range) & $\mathrm{cm}$ & 145 & $110-210 *$ \\
\hline Oksigen terlarut (Dissolved oxygen) & $\mathrm{mg} / \mathrm{L}$ & $2.58-8.39$ & $4-7^{* 1}$ \\
\hline $\mathrm{NH}_{3}$ & $\mathrm{mg} / \mathrm{L}$ & $0.0095-0.2652$ & $0.30^{* *}$ \\
\hline $\mathrm{NO}_{2}$ & $\mathrm{mg} / \mathrm{L}$ & $0.0009-2.7009$ & $\left.0.25^{*}\right)$ \\
\hline $\mathrm{NO}_{3}$ & $\mathrm{mg} / \mathrm{L}$ & $0.0025-1.2646$ & $0.008^{* * *}$ \\
\hline $\mathrm{PO}_{4}$ & $\mathrm{mg} / \mathrm{L}$ & $<0.0025-1.5758$ & $0.015^{* *}$ \\
\hline $\mathrm{Fe}$ & $\mathrm{mg} / \mathrm{L}$ & $0.0002-0.0156$ & $0.01^{*}$ \\
\hline Padatan tersuspensi total (Total suspended solid) & $\mathrm{mg} / \mathrm{L}$ & $10-124$ & $<25^{* * *}$ \\
\hline Bahan organik total (Total organic matter) & $\mathrm{mg} / \mathrm{L}$ & $30.51-51.09$ & $29.50 *$ \\
\hline
\end{tabular}

Sumber (Source): ") Poernomo (1992); *) Kementerian Kependudukan dan Lingkungan Hidup (2004) (Ministry of Demography and Live Environment (2004); ${ }^{* * *}$ Alabaster \& Lioyd (1982) dalam Effendi (2003)

meningkatnya $\mathrm{pH}$, suhu, dan salinitas dengan kesadahan air tambak yang rendah.

Nilai konsentrasi $\mathrm{NO}_{2}$ di lokasi survai 0,0009-2,7009 mg/L, umumnya masih baik sebagai media budidaya tambak. Konsentrasi $\mathrm{NO}_{2}$ optimum tambak udang $0,25 \mathrm{mg} / \mathrm{L}$ (Poernomo, 1992). Tingginya nilai konsentrasi $\mathrm{NO}_{2} 2,7009 \mathrm{mg} / \mathrm{L}$, didapatkan di tambak udang vaname intensif yang akan dipanen. Di dasar perairan tambak tersebut terdapat penumpukan endapan bahan organik yang berasal dari sisa pakan udang, diduga dapat menghambat proses nitrifikasi yaitu dalam bentuk peralihan antara amonia dan nitrat serta antara nitrat dan gas nitrogen dalam proses denitrifikasi pada kondisi anaerob. Menurut Effendi (2003), sumber nitrit dapat berupa limbah industri dan limbah domestik serta di perairan, konsentrasi nitrit relatif kecil karena segera dioksidasi menjadi nitrat. Perairan alami umumnya mengandung $\mathrm{NO}_{2} 0,001 \mathrm{mg} / \mathrm{L}$ dan sebaiknya tidak melebihi 0,06 mg/L (Canadian Council of Resource and Environment Ministers, 1987).

Nilai konsentrasi $\mathrm{NO}_{3}$ di lokasi survai 0,0025-1,2646 mg/L, masih baik sebagai media budidaya tambak. Tingginya konsentrasi $\mathrm{NO}_{3}$ 1,2646 mg/L, didapatkan di tambak udang vaname intensif yang akan dipanen. Penerapan tambak intensif, konsentrasi nitrat yang tinggi tidak diperlukan karena dapat menurunkan kualitas air. Konsentrasi nitrat $0,0025 \mathrm{mg} / \mathrm{L}$, didapatkan di tambak bandeng tradisional. Untuk tambak tradisional, konsentrasi nitrat perlu ditingkatkan melalui pemupukan untuk menstimulir pertumbuhan klekap, plankton dan lumut sebagai pakan alami utama bagi ikan dan udang. Nitrat tidak bersifat toksik terhadap organisme akuatik dan konsentrasi nitrat lebih dari $0,2 \mathrm{mg} / \mathrm{L}$ di perairan, dapat mengakibatkan eutrofikasi, yang berdampak blooming terhadap alga dan 
tanaman air. Konsentrasi nitrat air laut yang dipersyaratkan untuk kehidupan biota laut yaitu 0,008 mg/L (Effendi, 2003; KLH, 2004).

Konsentrasi fosfat $\left(\mathrm{PO}_{4}\right)$ dalam bentuk ortofosfat, sumber nutrien utama fosfor yang langsung dimanfaatkan tanaman air, klekap, plankton, dan lumut di tambak. Unsur ini menjadi faktor pembatas dan sangat mempengaruhi tingkat produktivitas perairan. Konsentrasi $\mathrm{PO}_{4}$ di lokasi survai $<0,0025$ $1,5758 \mathrm{mg} / \mathrm{L}$, masih baik sebagai media budidaya tambak. Tingginya nilai tersebut ( $1,5758 \mathrm{mg} / \mathrm{L})$, didapatkan di tambak udang vaname intensif yang akan dipanen. Konsentrasi fosfor di perairan alami 0,005-0,02 $\mathrm{mg} / \mathrm{L}$ dan di air tanah $0,02 \mathrm{mg} / \mathrm{L}$. Konsentrasi fosfor total di perairan alami jarang yang melebihi dari $1 \mathrm{mg} / \mathrm{L}$ (Boyd, 1988). Menurut Effendi (2003), terdapat 3 tingkat kesuburan perairan yaitu tingkat kesuburan rendah dengan konsentrasi fosfat total 0-0,02 mg/L; tingkat kesuburan sedang dengan konsentrasi fosfat total $0,021-0,05 \mathrm{mg} / \mathrm{L}$; dan tingkat kesuburan tinggi dengan konsentrasi fosfat total 0,051-0,1 mg/L. Konsentrasi fosfat air tambak sangat diperlukan bagi kegiatan tambak tradisional yang memerlukan pakan alami untuk hidup dan tumbuhnya ikan dan udang, tetapi kurang diperlukan bagi kegiatan budidaya tambak intensif yang hanya mengutamakan pakan buatan. Menurut KLH (2004), konsentrasi fosfat air laut yang dipersyaratkan untuk kehidupan biota laut $0,015 \mathrm{mg} / \mathrm{L}$.

Besi dalam bentuk kation ferro $\left(\mathrm{Fe}^{2+}\right)$ hanya didapatkan di perairan anaerob dan terjadi akibat proses dekomposisi bahan organik yang berlebihan. Konsentrasi besi $\left(\mathrm{Fe}^{2+}\right)$ di lokasi survai 0,0002-0,0156 mg/L dan masih baik untuk kegiatan budidaya tambak. Tingginya nilai tersebut $(0,0156 \mathrm{mg} / \mathrm{L})$, didapatkan di tambak bandeng tradisional kawasan mangrove dan semak belukar yaitu hasil oksidasi pirit yang berlangsung secara kimiawi dan biologis. Saat terjadi kondisi anaerob, ion besi ferri $\left(\mathrm{Fe}^{3+}\right)$ mereduksi menjadi ion besi ferro $\left(\mathrm{Fe}^{2+}\right)$ yang larut dan melepaskan fosfat sebagai sumber nutrien utama fosfor di perairan (Brown, 1987). Konsentrasi besi di perairan alami 0,05-0,2 mg/L dan konsentrasi besi > 1,0 mg/L, membahayakan kehidupan organisme akuatik (Boyd, 1988; Moore, 1991). Menurut Poernomo (1988), konsentrasi $\mathrm{Fe}^{2+}$ yang dipersyaratkan sebagai mutu air bagi tambak udang 0,01-0,03 mg/L.
Konsentrasi bahan organik total di lokasi survai 30,51-51,09 mg/L dan padatan tersuspensi total 10-124 mg/L. Kisaran nilai konsentrasi bahan organik total dan padatan tersuspensi total yang didapatkan masih baik sebagai media budidaya tambak, tingginya nilai kekeruhan akibat lumpur halus, didapatkan di kawasan tambak dekat muara sungai. Menurut Effendi (2003), padatan tersuspensi total yaitu bahan-bahan tersuspensi berukuran diameter $>1 \mu \mathrm{m}$, tertahan pada saringan millipore berdiameter pori 0,45 $\mu \mathrm{m}$. Padatan tersuspensi total berupa lumpur, pasir halus dan jasad renik yang melayanglayang di perairan. Bahan-bahan tersuspensi di perairan alami tidak bersifat tosik, jika berlebihan dapat meningkatkan nilai kekeruhan, yang berpengaruh terhadap proses fotosintesis. Perairan berkandungan bahan organik total di atas $26 \mathrm{mg} / \mathrm{L}$, tergolong subur (Reid, 1961).

Terdapat unit pertambakan di 6 kecamatan yaitu Kecamatan Sungai Pinyuh, Sungai Kunyit, Mempawah Hilir, Mempawah Timur, Segedong, dan Kecamatan Siantan, dapat dijangkau dengan kendaraan roda 2 dan 4, dekat jalan raya yang menghubungkan antar kecamatan, Kabupaten dan Kota Pontianak, sehingga transportasi benih, sarana produksi tambak, produksi udang, bandeng, dan rumput laut saat panen mudah terjangkau. Terdapat beberapa unit hatcheri udang, benih bandeng, dan rumput laut secara alami yang memadai untuk kebutuhan pembudidaya tambak. Bandeng dan rumput laut hanya dipasarkan antar kecamatan dan kabupaten, udang dipasarkan melalui pengumpul dan dijual ke eksportir di Kota Pontianak serta siap untuk diekspor, sedangkan udang hasil budidaya tambak intensif oleh pengusaha langsung diekspor.

\section{Lokasi Pengembangan Budidaya Tambak}

Dari hasil skoring dan pembobotan biofisik lokasi, analisis kualitas tanah dan air, curah hujan, serta didukung oleh kondisi lokasi penelitian dan status peruntukan lahan, infrastruktur dan aspek penunjang lainnya, maka tingkat kesesuaian lokasi budidaya tambak dapat diidentifikasi dan disajikan dalam bentuk peta kesesuaian lokasi (Gambar 2). Dari hasil analisis tersebut dengan mempertimbangkan aspek jalur hijau, dapat diestimasi luas tambak yang ada di wilayah pesisir Kabupaten Pontianak 497,077 ha. Yang 

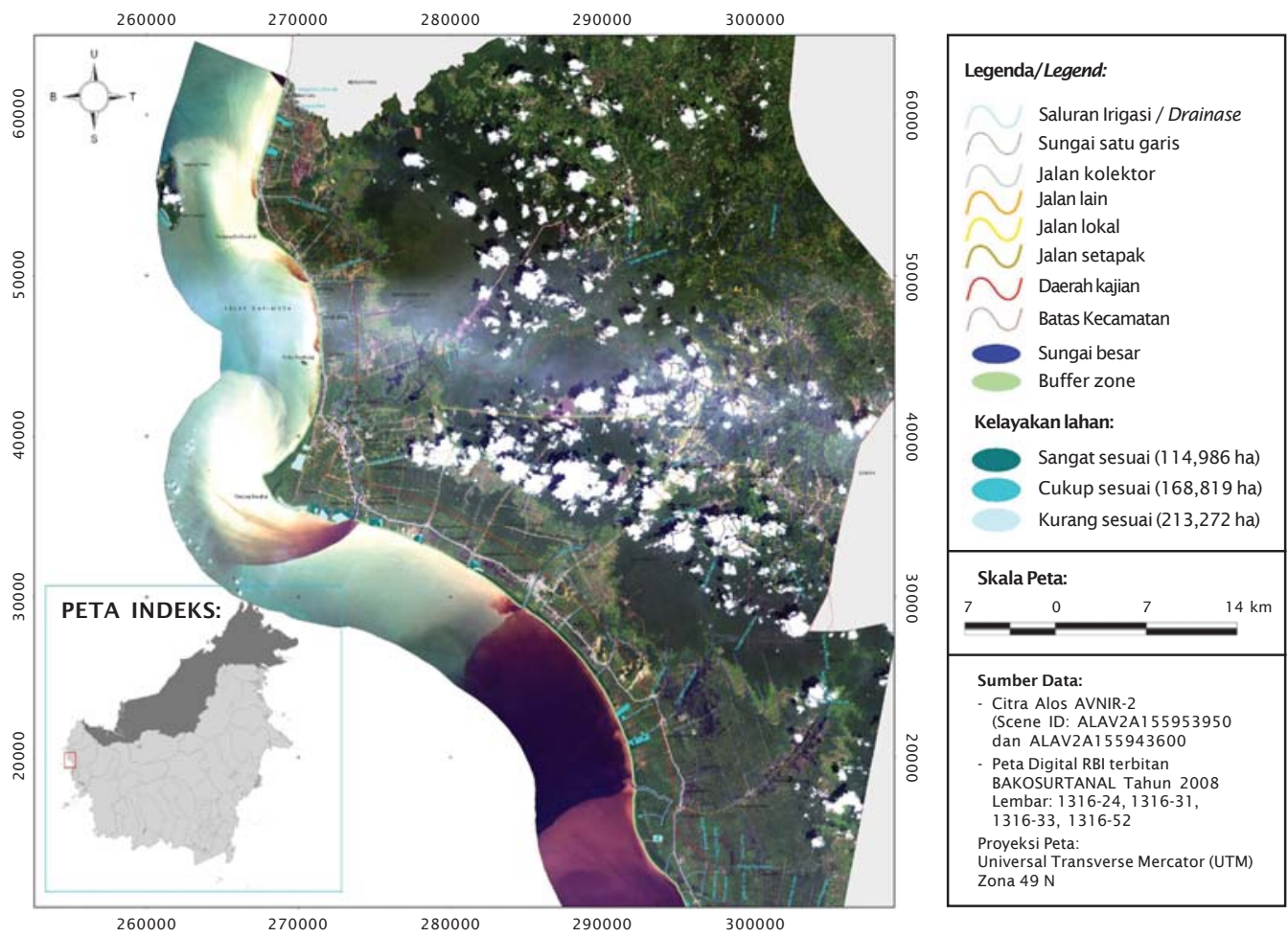

Gambar 2. Peta kesesuaian lokasi budidaya tambak di Kabupaten Pontianak, Kalimantan Barat

Figure 2. Map of suitability for brackhiswater pond in the Pontianak Regency, West Kalimantan

tergolong sangat sesuai ( 114,986 ha), cukup sesuai $(168,819 \mathrm{ha})$, tersebar di wilayah pesisir Kecamatan Sungai Pinyuh, Sungai Kunyit, Mempawah Hilir, dan Mempawah Timur, sedangkan yang kurang sesuai $(213,272 \mathrm{ha})$.

Lebar jalur hijau minimal $130 \times$ nilai ratarata perbedaan air pasang tertinggi dan terendah setempat $(\mathrm{m})$ yang diukur dari garis pantai saat air surut terendah dan lebar jalur hijau di tepi sungai minimal berjarak 100 $\mathrm{m}$ dari kiri dan kanan sungai besar serta $50 \mathrm{~m}$ dari kiri dan kanan sungai kecil yang berada di luar pemukiman. Dengan perbedaan pasang surut sebesar $145 \mathrm{~cm}$, maka lebar jalur hijau di kawasan sepanjang pantai Kabupaten Pontianak adalah 188,5 m.

Untuk pengembangan usaha budidaya tambak yang ramah lingkungan dan berkelanjutan, maka potensi yang ada sekiranya tidak dimanfaatkan seluruhnya, harus disediakan untuk kawasan penyangga, saluran irigasi tambak, rumah jaga dan sarana produksi tambak, dan lain-lain. Lokasi yang tingkat kesesuaiannya tinggi digunakan untuk pengembangan budidaya udang dengan sistem tradisional plus hingga semi intensif, yang tingkat kesesuaiannya sedang digunakan untuk kegiatan budidaya udang (monokultur) atau udang bersama bandeng (polikultur) dengan sistem tradisional hingga tradisional plus, dan yang tingkat kesesuaiannya rendah digunakan untuk kegiatan budidaya bandeng (monokultur) atau bandeng bersama rumput laut (polikultur) dengan sistem tradisional. Namun masih banyak yang harus diperbaiki seperti desain, tataletak dan konstruksi disesuaikan teknologi yang diterapkan, saluran irigasi tambak, tandon tambak dilengkapi dengan biofilter dan faktor lainnya.

\section{KESIMPULAN}

Memanfaatkan data inderaja (ALOS AVNIR2) yang diintegrasikan dengan data lapangan dan dianalisis dengan SIG, bahwa tambak yang ada di wilayah pesisir Kabupaten Pontianak 
seluas 497,077 ha, tambak yang tergolong sangat sesuai (S1) seluas 114,986 ha, cukup sesuai (S2) seluas 168,819 ha tersebar di wilayah pesisir Kecamatan Sungai Pinyuh, Sungai Kunyit, Mempawah Hilir, dan Mempawah Timur dan kurang sesuai seluas 213,272 ha terdapat di Kecamatan Segedong dan Siantan. Kondisi biofisik, kualitas tanah dan air di lokasi penelitian dinilai masih baik untuk kegiatan budidaya tambak. Kawasan pertambakan di sepanjang pantai yang telah disurvai, perlu tindakan merehabilitasi hutan mangrove yang semakin menipis sebagai daerah penyangga dan jalur hijau untuk melindungi pertambakan di sekitarnya.

\section{DAFTAR ACUAN}

Anonim. 2003a. Masterplan Pengembangan Budidaya Air Payau di Indonesia. Provinsi Kalimantan Barat. Direktorat Jenderal Perikanan, Jakarta, 397 hlm.

Anonim. 2003b. Kalimantan Barat Dalam Angka. Kerja sama Badan Pusat Statistik Provinsi Kalimantan Barat dan Pemerintah Daerah Provinsi Kalimantan Barat, $357 \mathrm{hlm}$.

Anonim. 2007. Rencana Tataruang Wilayah Kabupaten Pontianak. Pemerintah Kabupaten Pontianak, Badan Perencanaan Pembangunan Daerah (BAPPEDA) Kabupaten Pontianak, $128 \mathrm{hlm}$.

APHA (American Public Health Association). 2005. Standart Methods for Examinition of Water and Wastewater. $21^{\text {st }}$ edition, Centennial edition. APHA-AWWA-WEF, Washington, D.C., 1,288 pp.

Bengen, D.G. 2004. Pedoman Teknis Pengenalan dan Pengelolaan Ekosistem Mangrove. Pusat Kajian Sumberdaya Pesisir dan Lautan, Institut Pertanian Bogor, Bogor, $59 \mathrm{hlm}$.

Boyd, C.E. 1988. Water Quality in Warmwater Fish Ponds. Fourth Printing. Auburn University Agricultural Experiment Station, Alabama, USA, $359 \mathrm{pp}$.

Brown, A.L. 1987. Freshwater Ecology. Heineman Educational Books, London, 163 pp.

Canadian Council of Resource and Environment Ministers. 1987. Canadian Water Quality. Canadian Council of Resource and Environment Ministers, Ontario, $92 \mathrm{pp}$.

Duivenbooden, N.V. 1995. Land Use Systems Analysis as A Tool in Land Use Planning, $176 \mathrm{pp}$.
Effendi, H. 2003. Telaah Kualitas Air Bagi Pengelolaan Sumberdaya dan lingkungan Perairan. Penerbit Kanisius (Anggota IKAPI), Yogyakarta, $258 \mathrm{hlm}$.

Hendiarti, N., Sadly, M., Frederik, M.C.G., Andiastuti, R., \& Sulaiman, A. 2006. Satelit Oseanografi. Riset dan Teknologi Pemantauan Dinamika Laut Indonesia. Badan Riset Kelautan dan Perikanan, Departemen Kelautan dan Perikanan, Jakarta, hlm. 20-46.

Hidayat, A., Soekardi, M., \& Ponidi. 1995. Kajian kesesuaian lahan untuk mendukung pembangunan perikanan pantai dan pertanian di daratan Kasipute-Lainea, Sulawesi Tenggara. Dalam Laporan Akhir Hasil Penelitian Potensi dan Hasil Kesesuaian Lahan untuk Pengembangan Perikanan Pantai (Tingkat Tinjau Mendalam) Daerah Kasipute-Lainea, Sulawesi Tenggara. Pusat Penelitian Tanah dan Agroklimat Bekerja sama dengan Proyek Pembinaan Kelembagaan Penelitian Pertanian Nasional, Jakarta, hlm. 96-162.

Karthik, M., Suri, J., Saharan, N., \& Biradar, R.S. 2005. Brackhiswater aquaculture site selection in Palghar Taluk, Thane District of Maharashtra, India, using the techniques of remote sensing and Geographical Information System. Aquacultural Engineering, 32: 285-302.

KLH. 2004. Keputusan Menteri Negara Kependudukan dan Lingkungan Hidup, No. 51 tahun 2004, tanggal 8 April 2004 tentang Baku Mutu Air Laut. Kementerian Lingkungan Hidup, Jakarta, $11 \mathrm{hlm}$.

Melville, M.D. 1993. Soil Laboratory Manual School of Geography, University of New South Wales, Sydney, $74 \mathrm{pp}$.

Moore, J.W. 1991. Inorganic Contaminants of Surface Water. SpringerVerlag, New York, $334 \mathrm{pp}$.

Morain, S. 1999. GIS Solution in Natural Resource Management: Balancing the Technical-Political Equation. On Word Press. USA, $361 \mathrm{pp}$.

Noor, M. 2004. Lahan Rawa. Sifat dan PengeIolaan Tanah Bermasalah Sulfat Masam. Edisi ke-1, cetakan 1, PT Raja Grafindo Persada, Jakarta, $229 \mathrm{hlm}$.

Poernomo, A. 1988. Pembuatan Tambak di Indonesia. Seri Pengembangan No. 7, 1988. Departemen Pertanian, Badan Penelitian dan Pengembangan Pertanian, Balai 
Penelitian Perikanan Budidaya Pantai, Maros, $30 \mathrm{hlm}$.

Poernomo, A. 1992. Pemilihan Lokasi Tambak Udang Berwawasan Lingkungan. Pusat Penelitian dan Pengembangan Perikanan, Jakarta, $40 \mathrm{hlm}$.

Radiarta, I.N., Saputra, A., \& Priono, B. 2005. Identifikasi kesesuaian lahan budidaya ikan dalam keramba jaring apung dengan aplikasi Sistem Informasi Geografis di Teluk Pangpang, Jawa Timur. J. Pen. Perik. Indonesia, 5(11): 31-42.

Reid, G.K. 1961. Ecology Inland Water Estuaries. Rein Hald Published Co. New York, 37 pp.

Tebbut, T.H.Y. 1992. Principles of Water Quality Control. Fourth edition. Pergamon Press, Oxford, $251 \mathrm{pp}$.

Treece, G.D. 2000. Site Selection. In Stickney, R.R. Encyclopedia of Aquaculture. John Wiley \& Sons, Inc., p. 869-879.
Utojo, Mustafa, A., Rachmansyah, \& Hasnawi. 2009. Penentuan lokasi pengembangan budidaya tambak berkelanjutan dengan aplikasi sistem informasi geografis di Kabupaten Lampung Selatan. Pusat Riset Perikanan Budidaya, Badan Riset Kelautan dan Perikanan, Jakarta, J. Ris. Akuakultur, 3(4): 407-423.

Widigdo, B. 2003. Permasalahan dalam budidaya udang dan solusinya. J. IImu-ilmu Perairan dan Perikanan Indonesia, 10(1): 18-23.

Wirasantosa, S. 2004. Pengawasan Ekosistem Laut dan Permasalahannya. Pengawasan Semakin Menggigit. Media Informasi dan Komunikasi Internal Ditjen Pengawasan Sumberdaya Kelautan dan Perikanan "Barracuda", 1(2): 33-37. 